\title{
Assessment of Ocean Prediction Model for Naval Operations Using Acoustic Preset
}

\author{
Peter C. Chu and Guillermo Amezaga \\ Naval Ocean Analysis and Prediction Laboratory, Department of Oceanography \\ Naval Postgraduate School, Monterey, CA 93943 \\ Eric L. Gottshall \\ Space and Naval Warfare System Command \\ San Diego, CA 92110 \\ David S. Cwalina \\ Naval Undersea Warfare Center, Newport, RI 02841
}

\begin{abstract}
The outcome of a battlefield engagement is often determined by the advantages and disadvantages held by each adversary. On the modern battlefield, the possessor of the best technology often has the upper hand, but only if that advanced technology is used properly and efficiently. In order to exploit this advantage and optimize the effectiveness of high technology sensor and weapon systems, it is essential to understand the impact on them by the environment. In the arena of Anti-Submarine Warfare (ASW), the ocean environment determines the performance of the acoustic sensors employed and the success of any associated weapon systems. Since acoustic sensors detect underwater sound waves, understanding how those waves propagate is crucial to knowing how the sensors will perform and being able to optimize their performance in a given situation. To gain this understanding, an accurate depiction of the ocean environment is necessary. How acoustic waves propagate from one location to another under water is determined by many factors, some of which are described by the sound speed profile (SSP). If the environmental properties of temperature and salinity are known over the entire depth range, the SSP can be compiled by using them in an empirical formula to calculate the expected sound speed in a vertical column of water. One way to determine these environmental properties is to measure them in situ, such as by conductivity-temperature-depth or expendable bathythermograph (XBT) casts. This method is not always tactically feasible and only gives the vertical profile at one
\end{abstract}

location producing a very limited picture of the regional ocean structure. Another method is to estimate the ocean conditions using numerical models. The valued-aided ocean prediction models to ASW is assessed in this study. Such quantitative analyses offer a means to optimize the ASW requirements and technical capabilities of new weapon systems. We use observed and modeled 3-D fields of temperature, salinity, and sound speed. Compare model profiles to observed profiles. Do ocean models predict the vertical features of the observational data? Run representative modeled and observed SSP profiles through Navy's acoustic models to see if there is an acoustic difference in propagation and weapon preset.

\section{INTRODUCTION}

An advanced version of the Navy's Modular Ocean Data Assimilation System (MODAS-2.1), was recently developed at the Naval Research Laboratory. Its data assimilation capabilities may be applied to a wide range of input data, including irregularly located in-situ sampling, satellite, and climatological data. Available measurements are incorporated into a threedimensional, gridded output field of temperature and salinity. The MODAS-2.1 products are used to generate the sound speed field for ocean acoustic 
modeling applications. Other derived fields, which may be generated and examined by the user, include two-dimensional and three-dimensional quantities such as vertical shear of geostrophic current, mixed layer depth, sonic layer depth, deep sound channel axis depth, depth excess, and critical depth. These are employed in a wide variety of naval applications.

The first generation of this system, MODAS1.0 , was initially designed in early 1990 's to perform deep-water analyses that produced outputs that supported deep-water anti-submarine warfare operations. However, MODAS-1.0 was constrained by depth deeper than 100 meters because it used climatological data was the original Generalized Digital Environmental Model (GDEM) established from the Master Observational Oceanographic Data Set (MOODS). The capabilities of MODAS-1.0 were increased when GDEM was initially augmented with shallow water data base (SWDB), but at the time, SWDB was limited to the northern hemisphere. The NOAA global database, which has less horizontal resolution than GDEM, was used as a second source for the first guess field in MODAS-1.0. In addition, in MODAS-1.0 some of the algorithms for processing and for performing interpolations designed for speed and efficiency in deep waters with the cost of making some assumptions about the topography. This shortcut method extended all observational profiles to a common depth, even if the depth was well below the ocean bottom depth, by splicing onto climatology. The error introduced using this shortcut method is amplified when this method is applied to shallow water regions.

Second generation, MODAS-2.1, was created to overcome the limitations of MODAS-1.0. One of the major implementations was the development of MODAS internal ocean climatology (Static MODAS climatology) for both deep and shallow depths. Static MODAS climatology is produced using the historical $T, S$ profile data, i.e., the MOODS. Static MODAS climatology covers the ocean globally to a minimum depth of 5 meters and has variable-horizontal resolution from 7.5-minute to 60-minute resolution. Static MODAS climatology also contains important statistical descriptors required for optimum analysis of observations that include bi-monthly means of temperature, coefficients for calculation of salinity from temperature, standard deviations of temperature and salinity, and coefficients for several models relating temperature and mixed layer depth to surface temperature and steric height anomaly. MODAS-2.1 performs optimum interpolation analysis for each depth above the ocean bottom separately.
A recent development is to use the MODAS temperature and salinity fields to initialize an ocean prediction model such as the Princeton Ocean Model. Thus, it is urgent to evaluate the MODAS salinity field as well as the thermocline/halocline structures. The South China Sea Monsoon Experiment (SCSMEX) provides a unique opportunity for such an evaluation. The SCSMEX data haven't been assimilated into MODAS. Hydrographic data acquired from SCSMEX for April through June 1998 are used to verify MODAS temperature and salinity products.

\section{SOUTH CHINA SEA}

The South China Sea (SCS) is a semi-enclosed tropical sea located between the Asian land mass to the north and west, the Philippine Islands to the east, Borneo to the southeast, and Indonesia to the south (Fig. 1), a total area of $3.5 \times 10^{6} \mathrm{~km}^{2}$. It includes the shallow Gulf of Thailand and connections to the East China Sea (through Taiwan Strait), the Pacific Ocean (through Luzon Strait), Sulu Sea, Java Sea (through Gasper and Karimata Straits) and to the Indian Ocean (through the Strait of Malacca). All of these straits are shallow except Luzon Strait whose maximum depth is $1800 \mathrm{~m}$. Consequently, the SCS is considered a semienclosed sea.

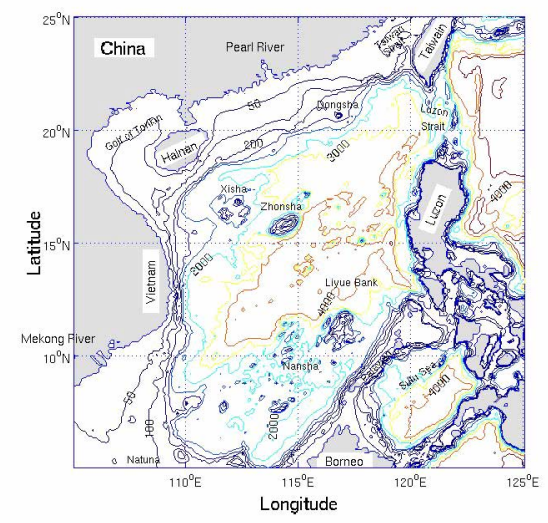

Fig. 1. Geography and isobaths showing the bottom topography of the South China Sea. Numbers show the depth in meter.

\section{SCSMEX}

SCSMEX is a large scale experiment to study the water and energy cycles of the Asian monsoon regions with the goal (SCSMEX Science Working Group, 1995): To provide a better understanding of the key physical processes responsible for the onset, maintenance and variability of the monsoon over Southeast Asia and southern China leading to 
improved predictions. It involves the participation of all major countries and regions of East and Southeast Asia, as well as Australia and the United States.

SCSMEX had both atmospheric and oceanic components. The oceanic intensive observational period (IOP) was from April through June 1998 with shipboard measurements, ATLAS moored array, and drifters. The hydrographic data collected during the SCSMEX IOP went through quality control procedures; such as, min-max check (e.g., disregarding any temperature data less than $-2^{\circ} \mathrm{C}$ and greater than $40^{\circ} \mathrm{C}$, error anomaly check. Fig. 2 shows the CTD stations during SCSMEX. [1].

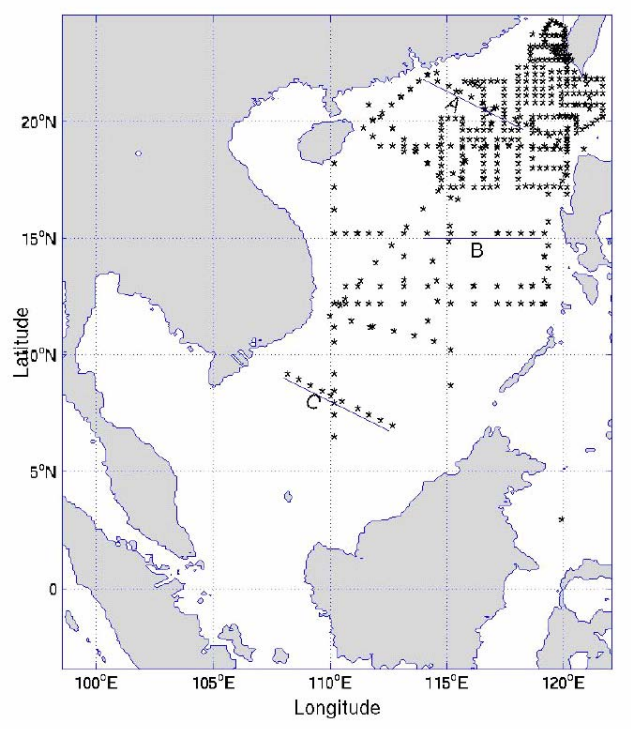

Fig. 2. The SCSMEX CTD stations.

\section{NAVY'S ACOUSTIC PRESET}

A Weapon Acoustic Preset Program (WAPP) is used to get automated, interactive means of generating Mk 48 and Mk 48 ADCAP acoustic presets and visualizing torpedo performance. It combines the $\mathrm{Mk}$ 48 Acoustic Preset Program (M48APP) and the Mk 48 ADCAP Acoustic Preset Program (MAAPP) into a single integrated package. The Royal Australian Navy as a part of the Collins Class Augmentation System also uses the M48APP, and the Royal Canadian Navy has changed the M48APP for Java. The program is based around a graphical user interface that allows the user to enter the environmental, tactical, target, and weapon data. With these user specified parameters, the program then performs a series of computations to generate accurate acoustic performance predictions. The output includes a ranked list-set of search depth, pitch angle, LD, and effectiveness values, an acoustic ray trace, and a signal excess map [2].

The Environmental Data Entry Module (EDE) is a simple GUI that allows the user to enter a variety of environmental parameters (Fig. 1). The sea surface fields allow the user to specify wind speed, wave height, and sea state based on either the World Meteorological or Beaufort scale conventions. The three fields are coupled so that an entry into one field will bring up the appropriate default values for the others. The bottom condition field allows the user to specify the bottom depth and to choose the bottom type from a list of possibilities. The bottom of the GUI is devoted to the water column characteristics and a sound speed profile. The temperature, sound speed, and depth are all in the appropriate English units. The volume scattering strength is in $\mathrm{dB}$. The additional fields include the latitude, longitude, the profile name, and the table group identifiers.

Once the environmental parameters have been entered then the user can move on to the Acoustic Module Preset Display. This GUI allows the user to specify a number of parameters about the weapon, the target, and the way the weapon should search (Fig. 3). The list-set on the right side of the GUI displays a series of search depths, pitch angles, laminar distances, and effectiveness values. The effectiveness values for the various presets are based on expected signal excess and ray trace computations. Both plots can be viewed from a pull-down menu. These provide a visual representation of the acoustic performance of the $\mathrm{Mk}$ 48.

In addition to automatically computing the most effective preset combination for a given set of environmental parameters, the program also allows the user to manually examine the effectiveness of any allowable preset combination via the signal excess and ray trace plots. The program also allows the user to save the tactical preset list and the accompanying environmental data. The data is stored locale to the weapon module and can be recalled later or transferred via a network to the combat control system. 


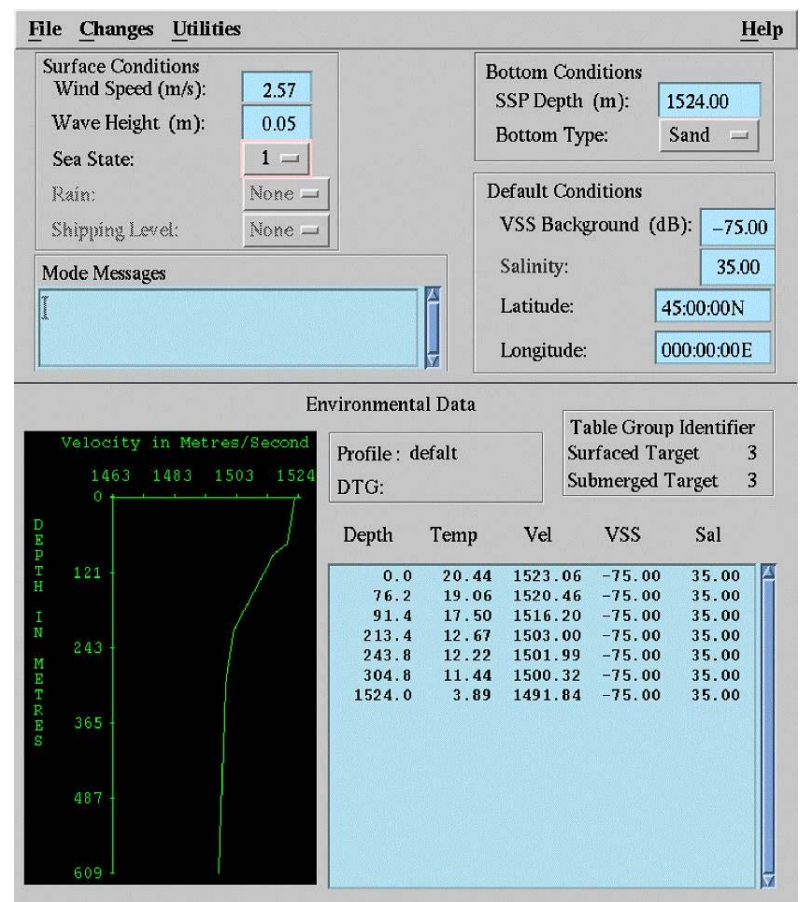

Fig. 3. Environmental data entry to WAPP.

\section{MODAS}

MODAS is one of the present U.S. Navy standard tools for production of three-dimensional grids of temperature and salinity, and derived quantities such as density, sound speed, and mixed layer depth (Fig. 4). It is a modular system for ocean analysis and is built from a series of FORTRAN programs and UNIX scripts that can be combined to perform desired tasks. MODAS was designed to combine observed ocean data with climatological information to produce a quality-controlled, gridded analysis field as output. The analysis uses an optimal interpolation (OI) data assimilation technique to combine various sources of data [3].

\subsection{Static and Dynamic MODAS}

MODAS has two modes of usage; static MODAS and dynamic MODAS. Static MODAS climatology is an internal climatology used as MODAS' first guess field. The other mode is referred to as the dynamic MODAS, which combines locally observed and remote sensed ocean data with climatological information to produce a near real time gridded three-dimensional analysis field of the ocean temperature and salinity structure as an output. Grids of MODAS climatological statistics range from 30-minute resolution in the open ocean to 15 -minute resolution in shallow waters and 7.5-minute resolution near the coasts in shallow water regions.

\subsection{Synthetic Temperature and Salinity Profiles}

Traditional oceanographic observations, such as CTD, expendable bathythermograph (XBT), etc., are quite sparse and irregularly distributed in time and space. It becomes important to use satellite data in MODAS for establishing real-time three dimensional T, S fields. Satellite altimetry and SST provide global datasets useful for studying ocean dynamics and for ocean prediction. MODAS has a component for creating synthetic temperature and salinity profiles, which are the functions of parameters measured at the ocean surface such as satellite SST and SSH. These relationships were constructed using a least-squares regression analysis performed on archived historical database of temperature and salinity profiles (e.g., MOODS).

Three steps are used to establish regression relationships between the synthetic profiles and satellite SST and SSH: (a) computing regional empirical orthogonal functions (EOFs) from the historical temperature and salinity profiles, (b) expressing the $\mathrm{T}, \mathrm{S}$ profiles in terms of EOF series expansion, and (c) performing regression analysis on the profile amplitudes for each mode with the compactness of the EOF representation allowing the series to be truncated after only three terms while still retaining typically over $95 \%$ of the original variance.

\subsection{First Guess Fields}

The MODAS SST field uses the analysis from previous days field as the first guess, while the MODAS' two-dimensional SSH field uses a large-scale weighted average of 35 days of altimeter data as a first guess. The deviations calculated from the first guess field and the new observations are interpolated to produce a field of deviations from the first guess. Next, a final two-dimensional analysis is calculated by adding the field of deviations to the first guess field. When the model performs an optimum interpolation for the first time it uses the Static MODAS climatology for the SST first guess field and zero for the SSH first guess field. Every data after the first optimum interpolation it uses previous day's first guess field for SST and a large-scale weighted average is used for SSH. Synthetic profiles are generated at each location based on the last observation made at that location. If the remotely obtained SST and SSH for a location do not differ from the climatological data for that location, then climatology is used for that profile. Likewise, if the remotely obtained SST and SSH for a location differ from the climatological data for that location 
then the deviation at each depth are estimated. Adding these estimated deviations to the climatology produces the synthetic profiles.

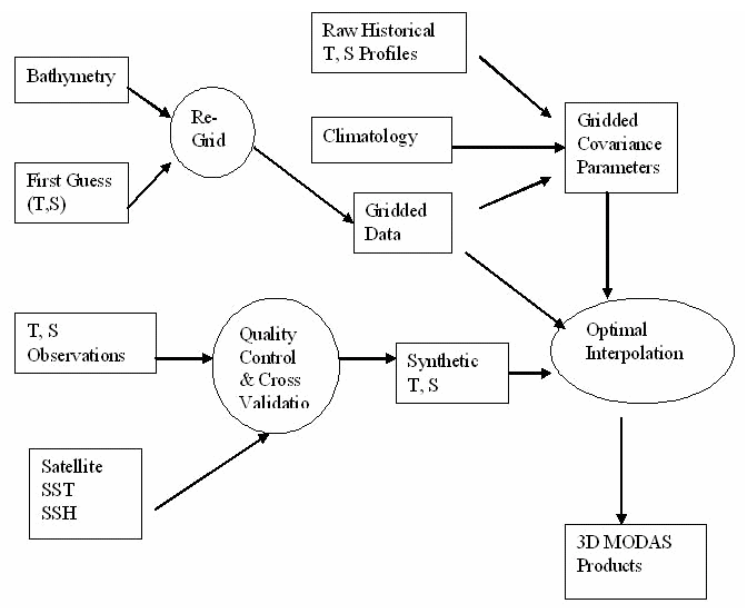

Fig. 4. Flow chart of MODAS operational procedure.

\section{METHODOLOGY OF VERIFICATION}

The observational data are located at depth $z$. We interpolate the MODAS data into the observational points $\left(x_{i}, y_{j}, z, t\right)$ and form a modeled data set.

\subsection{Error Statistics}

Let $\psi_{m}, \psi_{c}, \quad$ and $\psi_{o}$ be the variable $\psi$ (temperature, salinity, ...) obtained from MODAS, climatological dataset, and observation, Difference of $\psi$ between modeled and observed values

$$
\Delta_{m} \psi\left(x_{i}, y_{j}, z, t\right)=\psi_{m}\left(x_{i}, y_{j}, z, t\right)-\psi_{o}\left(x_{i}, y_{j}, z, t\right),
$$

represents the model error. Difference of $\psi$ between climatological and observed values

$$
\Delta_{c} \psi\left(x_{i}, y_{j}, z, t\right)=\psi_{c}\left(x_{i}, y_{j}, z, t\right)-\psi_{o}\left(x_{i}, y_{j}, z, t\right),
$$

represents the prediction error using the climatological values. We may take the probability histogram of $\Delta \psi$ as the error distribution.

The parameters: bias, mean-square-error (MSE), and root-mean-square error (RMSE) for the MODAS model

$$
\begin{gathered}
\operatorname{BIAS}(m, o)=\frac{1}{N} \sum_{i} \sum_{j} \Delta \psi_{m}\left(x_{i}, y_{j}, z, t\right), \\
\operatorname{MSE}(m, o)=\frac{1}{N} \sum_{i} \sum_{j}\left[\Delta_{m} \psi\left(x_{i}, y_{j}, z, t\right)\right]^{2},
\end{gathered}
$$

$$
\operatorname{RMSE}(m, o)=\sqrt{\operatorname{MSE}(m, o)},
$$

and for the reference model (e.g., climatology),

$$
\begin{array}{r}
\operatorname{BIAS}(c, o)=\frac{1}{N} \sum_{i} \sum_{j} \Delta \psi_{c}\left(x_{i}, y_{j}, z, t\right), \\
\operatorname{MSE}(c, o)=\frac{1}{N} \sum_{i} \sum_{j}\left[\Delta_{c} \psi\left(x_{i}, y_{j}, z, t\right)\right]^{2}, \\
\operatorname{RMSE}(c, o)=\sqrt{\operatorname{MSE}(c, o)},
\end{array}
$$

are commonly used for evaluation of the model performance. Here $N$ is the total number of horizontal points ([4]. [5]).

\section{EVALUATION OF MODAS}

Historical data is required to understand the basic physics of the oceanography and meteorology in order to properly optimize a model and to determine the forcing function to a specific basin. Real-time data is required when running in operational modes such as SWAFS and NCOM. In addition to ocean modeling, NAVOCEANO also perform direct analysis on data to construct products in the Warfare Support Center (WSC). Fig. 4 shows the procedure of the evaluation.

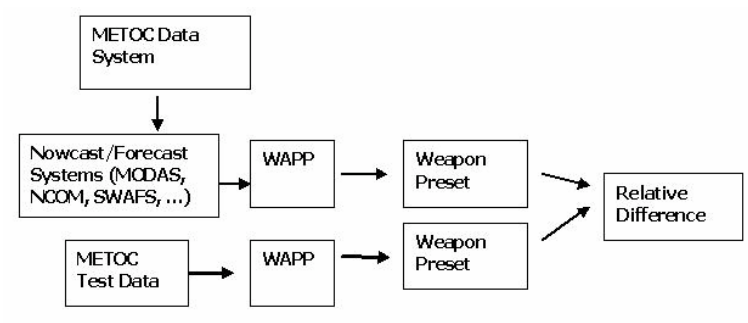

Fig. 5. . Evaluation of MODAS

We compare the MODAS data against the SCSMEX CTD data for the whole domain to verify the model capability.

The easiest way to verify MODAS performance is to plot the MODAS data against SCSMEX CTD data (Fig.5). The scatter diagrams for temperature show the points clustering around the line of $T_{m}=T_{o}$. The scatter diagrams for salinity show more spreading-out of the points around the line of $S_{m}=S_{o}$. This result indicates 
better performance in temperature nowcast than in salinity nowcast.

The model errors for temperature and salinity nowcast have Gaussian-type distribution with zero mean for temperature and $-0.048 \mathrm{ppt}$ for salinity and with standard deviation (STD) of $0.98^{\circ} \mathrm{C}$ for temperature and 0.22 ppt for salinity (Fig. 6). This result indicates that MODAS usually under-predicts the salinity.
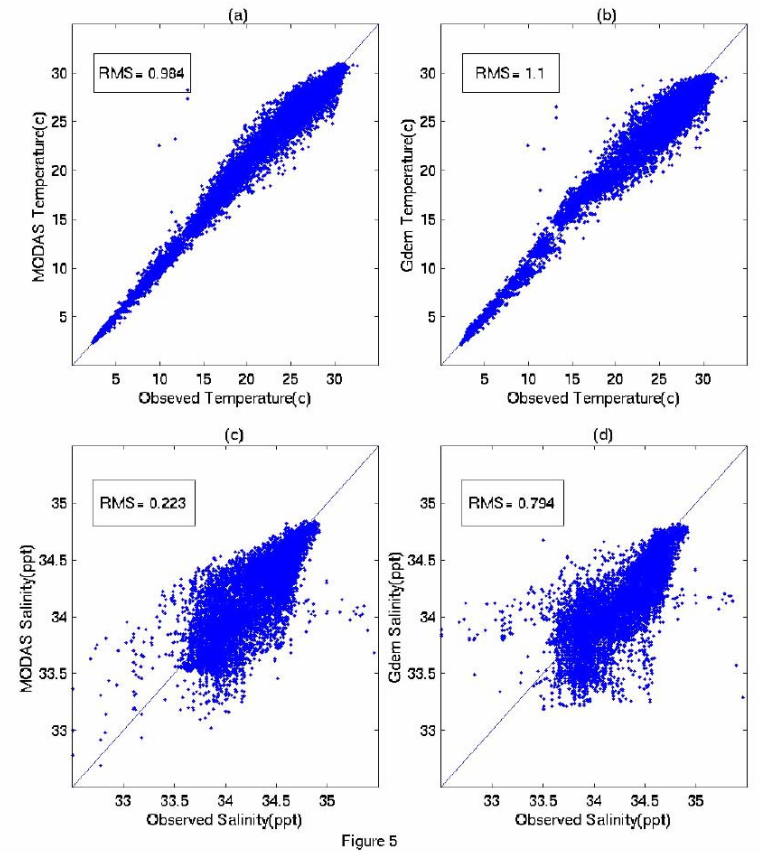

Fig. 6. Scatter diagrams of the MODAS versus SCSMEX data: (a) temperature, and (b) salinity.

\subsection{Error Estimation}

The RMSE of temperature (Fig. 7a,) between the MODAS and SCSMEX data increases with depth rapidly from $0.55^{\circ} \mathrm{C}$ at the surface to $1.72^{\circ} \mathrm{C}$ at $62.5 \mathrm{~m}$ and then reduces with depth to near $0.03^{\circ} \mathrm{C}$ at $3000 \mathrm{~m}$ deep. The RMSE of salinity (Fig. 7b, Table 3 ) between the MODAS and the SCSMEX data has a maximum value $(0.347 \mathrm{ppt})$ at the surface. It decreases to a very small value $(0.009 \mathrm{ppt})$ at $3000 \mathrm{~m}$.

The MODAS mean temperature is slightly $\left(0.1^{\circ} \mathrm{C}\right)$ cooler than the SCSMEX mean temperature at the surface and $2.5 \mathrm{~m}$ depth. The difference decreases with depth. Below $30 \mathrm{~m}$ depth, the MODAS mean temperature becomes warmer than the SCSMEX mean temperature with the maximum BIAS (about $0.6^{\circ} \mathrm{C}$ warmer) at $100 \mathrm{~m}$ deep. Below $100 \mathrm{~m}$ depth, the warm BIAS decreases with depth to $500 \mathrm{~m}$. Below $500 \mathrm{~m}$, the BIAS becomes very small (less than $0.1^{\circ} \mathrm{C}$ ).

The MODAS mean salinity is less than the SCSMEX mean salinity at almost all depths (Fig. 8b). At the surface, the MODAS salinity is less (0.117 ppt.) than the SCSMEX mean salinity. Such a bias increases with depth to a maximum value of $0.148 \mathrm{ppt}$ at $62.5 \mathrm{~m}$ depth and decreases with depth below $62.5 \mathrm{~m}$ depth.

The skill score of the temperature nowcast (Fig. 9a) is positive except at depth between 1750 and $2250 \mathrm{~m}$. The skill score of the salinity nowcast (Fig. 9b) is less than that of the temperature nowcast especially at depth between 300 and 400, where the skill score is negative.
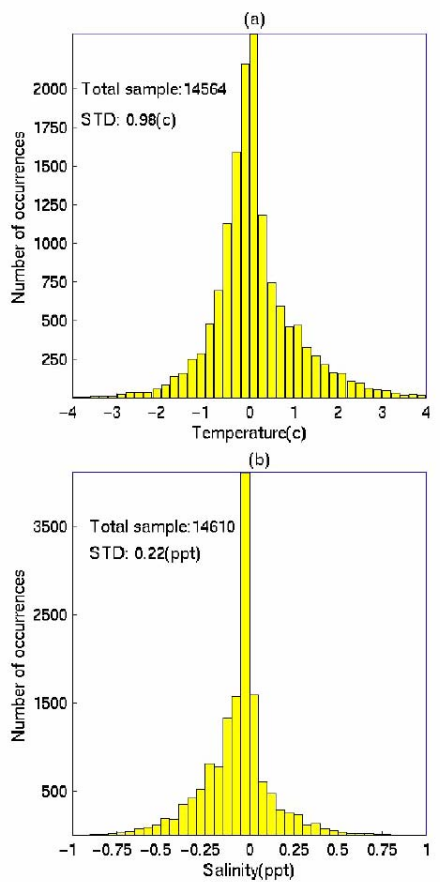

Fig.7. Histogram of MODAS errors of (a) temperature $\left({ }^{\circ} \mathrm{C}\right)$ and (b) salinity (ppt).

\section{CAPABILITY FOR NOWCASTING THERMOCLINE AND HALOCLINE STRUCTURE}

It is very difficult for any model to nowcast thermocline and halocline structure. To test MODAS capability on this issue, we compare the MODAS and SCSMEX T, S cross-sections at three observational lags (Fig. 2) and T, S time series at five mooring stations.

\subsection{Observational Lags}

We compare the MODAS fields to the SCSMEX data at three observational lags: Lag-A conducted by R/V Shiyan-3 on April 25-26, 1998; Lag-B conducted by R/V Haijian-74 on May 3, 1998; and Lag-C conducted by R/V Haijian-74 on April 27-29, 1998. 

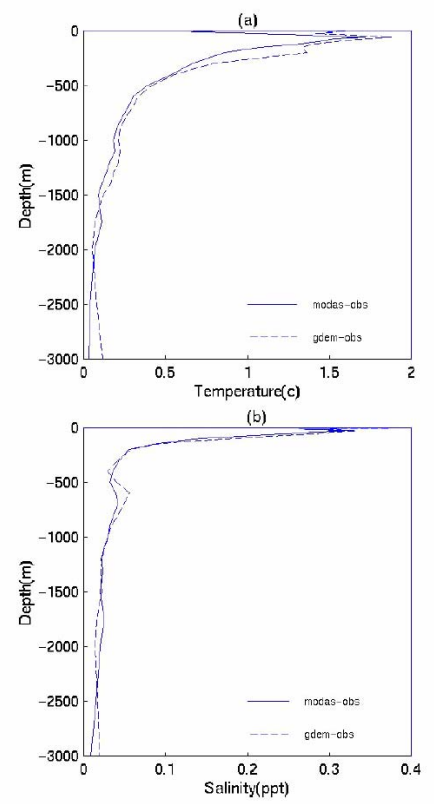

Fig. 8. The RMSE between the MODAS and SCSMEX data (solid) and between the GDEM and SCSMEX data (dotted): (a) temperature $\left({ }^{\circ} \mathrm{C}\right)$, and (b) salinity (ppt).
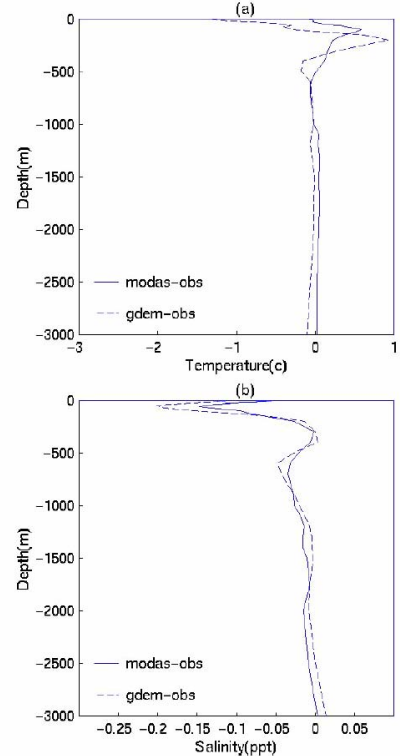

Fig. 9. The BIAS between the MODAS and SCSMEX data (solid) and between the GDEM and SCSMEX data (dotted): (a) temperature $\left({ }^{\circ} \mathrm{C}\right.$ ), and (b) salinity (ppt).
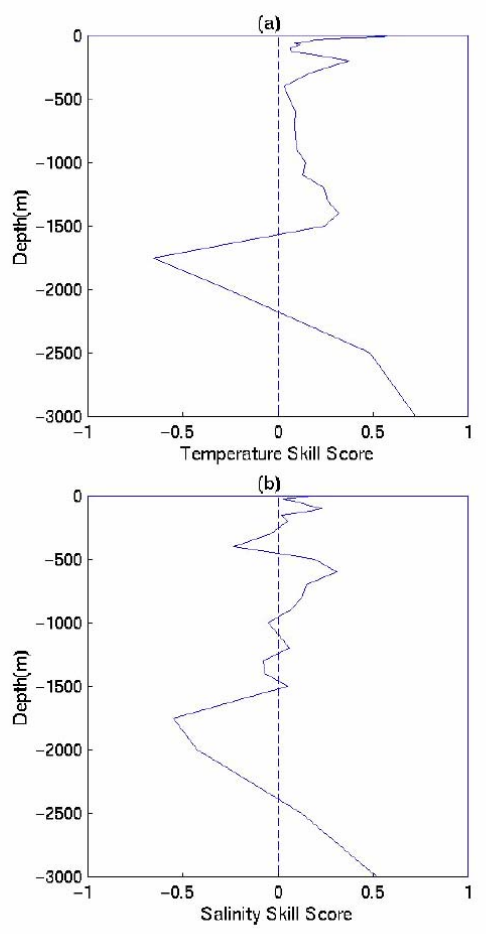

Fig. 10. Skill score of MODAS.

\subsubsection{Lag-A}

The lag-A is across the northwest SCS shelf from the Pearl River (third largest river in China) mouth toward northwest tip of Luzon Island. Vertical temperature cross-sections of MODAS (Fig. 10a) and SCSMEX (Fig. 10b) and salinity cross-sections of MODAS (Fig. 10d) and SCSMEX (Fig. 10e) show little difference near the surface, and large difference in the thermocline (comparing Figs. 11a with 11b) and halocline (comparing Figs. 11d with 11e), which indicates that MODAS has a strong capability to nowcast surface $T, S$ fields, and a weak capability to nowcast $T, S$ fields near the thermocline and halocline. Thermocline and halocline identified from the MODAS temperature (Fig. 10a) and salinity (Fig. 10d) cross-sections are weaker than SCSMEX data (Figs. $10 \mathrm{~b}$ and 10e). The maximum error in the MODAS temperature field (Fig. 10c) is around $3{ }^{\circ} \mathrm{C}$ at 50-70 $\mathrm{m}$ deep (in the thermocline) near the shelf break. The maximum error in the MODAS salinity field (Fig. $10 \mathrm{f}$ ) is around $-0.2 \mathrm{ppt}$ in the halocline (25-50 $\mathrm{m}$ deep).

\subsubsection{Lag-B}

The lag-B is nearly along $15^{\circ} \mathrm{N}$ latitude. Vertical temperature cross-sections of MODAS (Fig. 12a) and SCSMEX (Fig. 12b) show little difference near the surface, and large difference in the thermocline 
(comparing Figs. 12a with 12b). Location of the thermocline identified from the MODAS temperature (Fig. 12a) coincides with that identified from the SCSMEX data (Fig. 12b). However, the vertical temperature gradient in the MODAS data is weaker than that in the SCSMEX data. The maximum temperature error $\left(3^{\circ} \mathrm{C}\right)$ occurs at $50-100 \mathrm{~m}$ deep eastern part of the cross-section (Stations 6-8, Fig. 12c), where the strongest thermocline presents (Fig. $12 b)$.

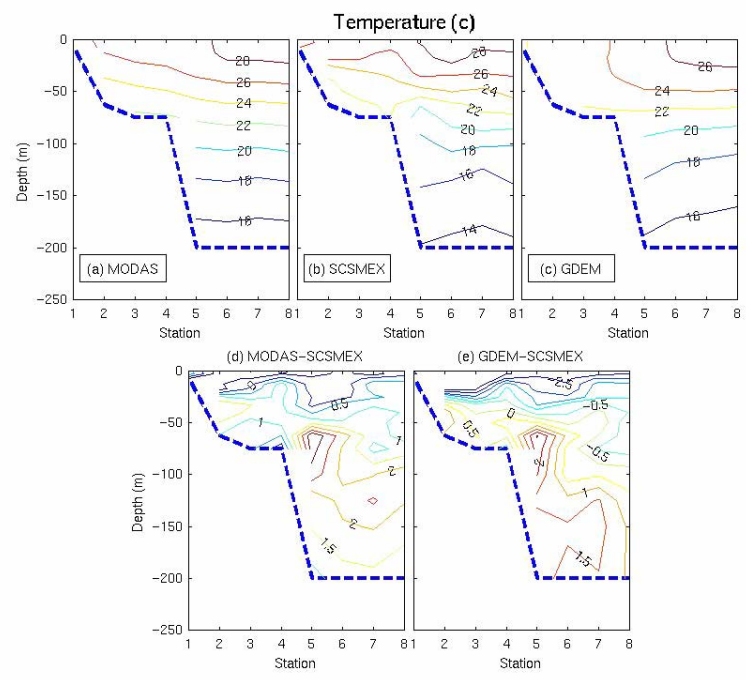

Fig. 11. Comparison between the MODAS and SCSMEX data along the lag-A cross-section: (a) MODAS temperature, (b) SCSMEX temperature, (c) MODAS temperature minus SCSMEX temperature, (d) MODAS salinity, (b) SCSMEX salinity, (c) MODAS salinity minus SCSMEX salinity.

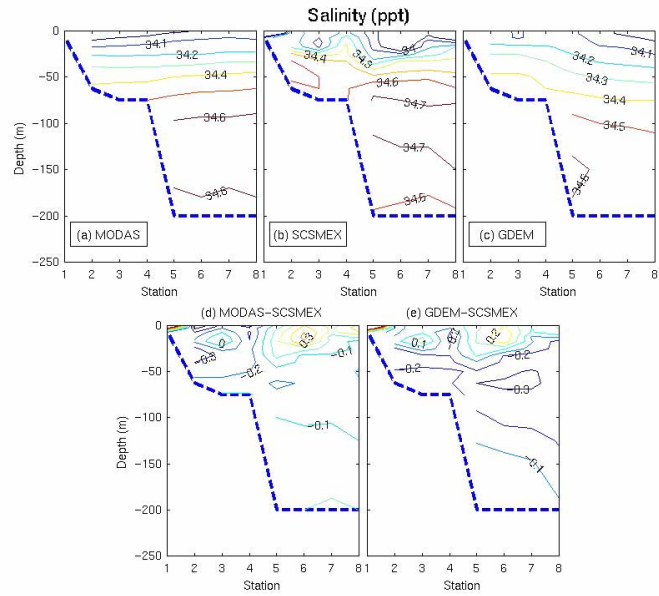

Fig. 12. Comparison between the MODAS and SCSMEX data along the lag-B cross-section: (a) MODAS temperature, (b) SCSMEX temperature, (c) MODAS temperature minus SCSMEX temperature, (d) MODAS salinity, (b) SCSMEX salinity, (c) MODAS salinity minus SCSMEX salinity.
Location of the halocline identified from the MODAS salinity (Fig. 12d) coincides with that identified from the SCSMEX data (Fig. 12e) in the eastern part. However, MODAS failed to nowcast the outcrop of the halocline in the western part (Fig. 12e). Two maximum salinity error centers appear in the halocline with one center in the western halocline outcropping area from the surface to $50 \mathrm{~m}$ depth $(-0.7 \mathrm{ppt})$ and the other in the eastern part (-0.6 ppt) at $50 \mathrm{~m}$ deep.

\subsubsection{Lag-C}

The lag-C is across the South Vietnam shelf from the Mekong River (largest river in the Indo-China Peninsula) mouth toward northwest tip of Borneo. Vertical temperature cross-sections of MODAS (Fig. 13a) and SCSMEX (Fig. 13b) and salinity crosssections of MODAS (Fig. 13d) and SCSMEX (Fig. 12e) show little difference in temperature near the surface, and large difference

in the thermocline (comparing Figs. 13a with 13b) and evident difference in salinity at the surface and in the halocline (comparing Figs. 13d with 13e).

Thermocline and halocline identified from the MODAS temperature (Fig. 13a) and salinity (Fig. 13d) cross-sections are weaker than SCSMEX data (Figs. $12 \mathrm{~b}$ and 12e). The maximum error in the MODAS temperature field (Fig. 12c) is around $2^{\circ} \mathrm{C}$ at $50-75 \mathrm{~m}$ deep (in the thermocline) near the shelf break. The maximum error in the MODAS salinity field (Fig. 11f) is around $-0.5 \mathrm{ppt}$ in the halocline (25-50 $\mathrm{m}$ deep).

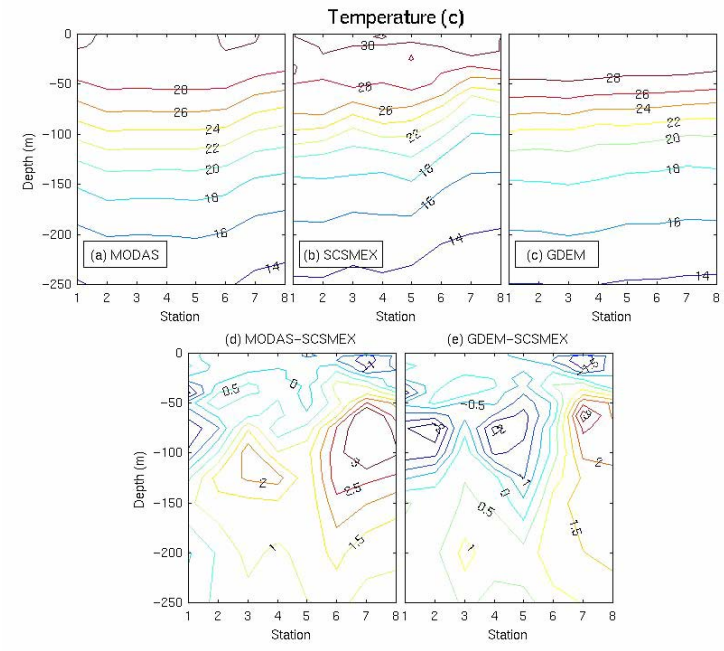

Fig. 13. Comparison between the MODAS and SCSMEX data along the lag-C cross-section: (a) MODAS temperature, (b) SCSMEX temperature, (c) MODAS temperature minus SCSMEX temperature, (d) MODAS salinity, (b) SCSMEX salinity, (c) MODAS salinity minus SCSMEX salinity.

9.2. Mooring Stations 
There are five mooring stations during SCSMEX. The comparison between MODAS and SCSMEX data was conducted at all the stations. We present the results at one mooring station $\left(114.38^{\circ} \mathrm{E}, 21.86^{\circ} \mathrm{N}\right)$ for illustration.

\subsubsection{General Evaluation}

Vertical-time cross-sections of temperature from MODAS (Fig. 14a) and from SCSMEX (Fig. 14b) show little difference near the surface, and large difference in the thermocline (comparing Figs. 13a with 13b), which confirms that MODAS has a strong capability to nowcast surface temperature field.

Thermocline and halocline identified from the MODAS temperature (Fig. 14a) and salinity (Fig. 14d) cross-sections are weaker than SCSMEX data (Figs. $14 \mathrm{~b}$ and $14 \mathrm{e})$. The maximum error in the MODAS temperature field (Fig. 14c) is around $2^{\circ} \mathrm{C}$ at $50 \mathrm{~m}$ deep (in the thermocline). The maximum error in the MODAS salinity field (Fig. 14f) is around $-0.2 \mathrm{ppt}$ in the halocline.

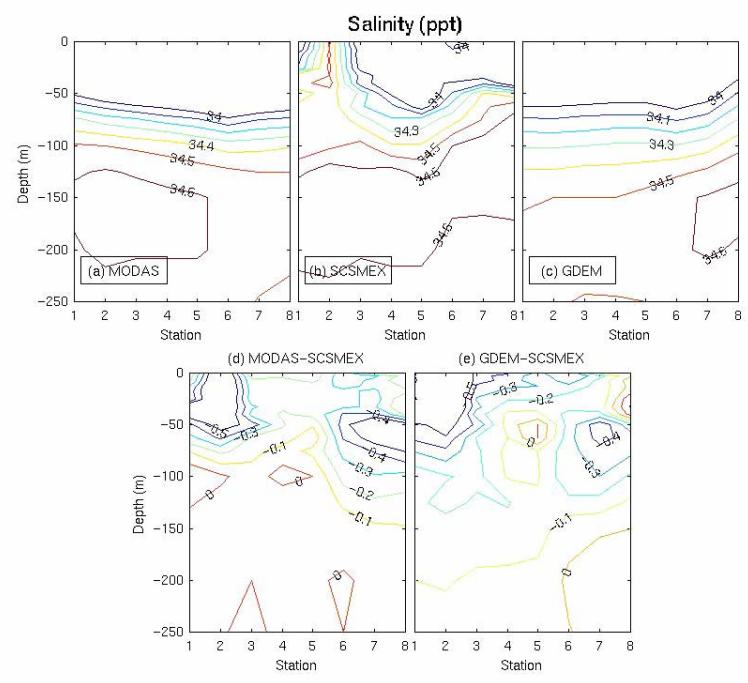

Fig. 14. Temporal-vertical cross-sections at the mooring station $\left(114.38^{\circ} \mathrm{E}, 21.86^{\circ} \mathrm{N}\right)$ : (a) MODAS temperature, (b) SCSMEX temperature, (c) MODAS temperature minus SCSMEX temperature, (d) MODAS salinity, (b) SCSMEX salinity, (c) MODAS salinity minus SCSMEX salinity.

\subsubsection{Thermocline Parameters}

Three parameters are computed for representing the thermocline/halocline characteristics: depth, gradient, and thickness. For thermocline, we calculate the vertical temperature gradient, $\partial T / \partial z$, use its maximum value as the thermocline gradient, identify the corresponding depth as the thermocline depth, and take the distance between $19^{\circ} \mathrm{C}$ and $28^{\circ} \mathrm{C}$ isotherms as the thermocline thickness. For halocline, it is hard to compute the vertical gradient since the SCSMEX salinity field shows patchiness at the surface (Fig. 13e). We identify the depth of $34.25 \mathrm{ppt}$ as the halocline depth, use the distance between 34.1 and $34.4 \mathrm{ppt}$ isolines as the halocline thickness, and take $0.3 \mathrm{ppt} /$ thickness as the halocline gradient.

The thermocline depth estimated from the MODAS temperature field is $10-40 \mathrm{~m}$ shallower than that from the SCSMEX data (Fig. 15a). The vertical temperature gradient across the thermocline computed from the MODAS field is around $0.14^{\circ} \mathrm{C} / \mathrm{m}$ (Fig. 14b), much weaker and (varying) slower than that calculated from the SCSMEX data $\left(0.19^{\circ}-0.27^{\circ} \mathrm{C} / \mathrm{m}\right)$. The thermocline thickness computed from the MODAS filed varies slowly around $80 \mathrm{~m}$, which falls in its temporal variation calculated from the SCSMEX data (40-100 $\mathrm{m})$.

\subsubsection{Halocline Parameters}

We computed three parameters to represent the halocline characteristics: halocline depth, salinity gradient across the halocline, and halocline thickness. The halocline depth estimated from the MODAS salinity field is always deeper than that from the SCSMEX data (Fig. 15d). The vertical salinity gradient across the halocline computed from the MODAS field is around $0.011 \mathrm{ppt} / \mathrm{m}$ (Fig. 14e), which is generally stronger than that calculated from the SCSMEX data $(0.0065-0.011 \mathrm{ppt} / \mathrm{m})$. The halocline thickness computed from the MODAS filed varies slowly around $30 \mathrm{~m}$, which is generally thinner than that calculated from the SCSMEX data (28-46 m).

\section{CONCLUSIONS}

(1) MODAS has the capability to provide temperature and salinity nowcast fields reasonably well. The model errors have a Gaussian-type distribution with mean temperature nearly zero and mean salinity of $-0.2 \mathrm{ppt}$.. The standard deviations of temperature and salinity errors are $0.98^{\circ} \mathrm{C}$ and 0.22 ppt., respectively.

(2) The skill score of the temperature nowcast is positive except at depth between 1750 and $2250 \mathrm{~m}$. The skill score of the salinity nowcast is less than that of the temperature nowcast especially at depth between 300 and $400 \mathrm{~m}$, where the skill score is negative.

(3) The MODAS mean temperature is slightly $\left(0.1^{\circ} \mathrm{C}\right)$ cooler than the SCSMEX mean temperature at the surface. Below $30 \mathrm{~m}$ deep, the MODAS mean 
temperature becomes warmer than the SCSMEX mean temperature with the maximum bias (about $0.6^{\circ} \mathrm{C}$ warmer) at $100 \mathrm{~m}$ deep. Below $100 \mathrm{~m}$ depth, the warm bias decreases with depth to less than $0.1^{\circ} \mathrm{C}$ below 500 $\mathrm{m}$ deep.

(4) The MODAS mean salinity is less than the SCSMEX mean salinity at all depths. This indicates that the MODAS under-estimates the salinity field. Such a bias increases with depth from $0.113 \mathrm{ppt}$ at the surface to a maximum value of $0.135 \mathrm{ppt}$ at $60 \mathrm{~m}$ depth and decreases with depth below $60 \mathrm{~m}$ deep.

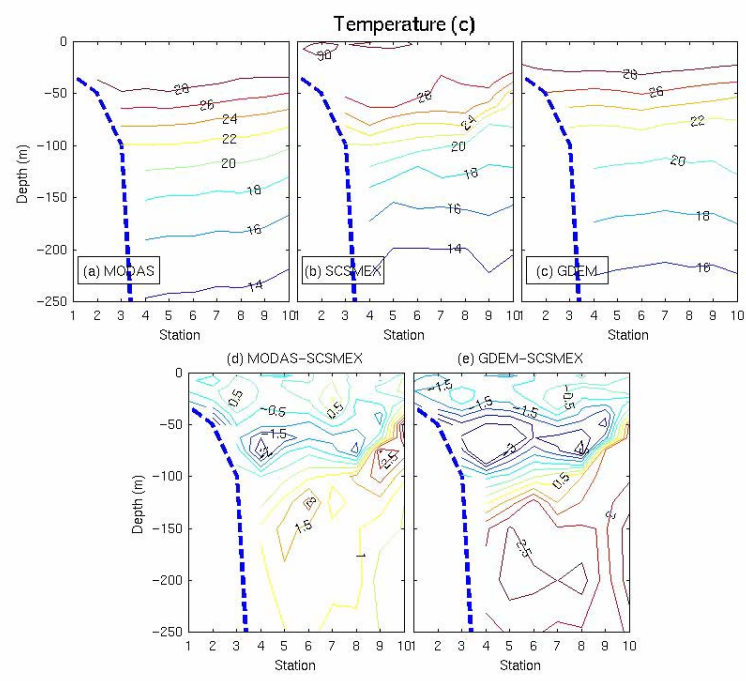

Fig. 15. Thermocline and halocline parameters determined from MODAS (dashed) and SCSMEX (solid) at the mooring station $\left(114.38^{\circ} \mathrm{E}, 21.86^{\circ} \mathrm{N}\right)$ : (a) thermocline depth, (b) thermocline gradient, (c) thermocline thickness, (d) halocline depth, (e) halocline gradient, and (f) halocline thickness.

(5) Thermocline and halocline identified from the MODAS temperature and salinity fields are weaker than the SCSMEX data. The maximum discrepancy between the two is in the thermocline and halocline. In outcropping halocline, the discrepancy becomes high (0.7 ppt along Lag-B).

(6) The thermocline depth estimated from the MODAS temperature field is $10-40 \mathrm{~m}$ shallower than that from the SCSMEX data. The vertical temperature gradient across the thermocline computed from the MODAS field is around $0.14^{\circ} \mathrm{C} / \mathrm{m}$, much weaker than that calculated from the SCSMEX data $\left(0.19^{\circ}-0.27^{\circ} \mathrm{C} / \mathrm{m}\right)$. The thermocline thickness computed from the MODAS filed varies slowly around $80 \mathrm{~m}$, which falls in its temporal variation calculated from the SCSMEX data $(40-100 \mathrm{~m})$.

(7) The halocline depth estimated from the MODAS salinity field is deeper than that from the SCSMEX data. Its thickness computed from the MODAS filed varies slowly around $30 \mathrm{~m}$, which is generally thinner than that calculated from the SCSMEX data (28-46 m).

\section{ACKNOWLEDGMENTS}

The authors wish to thank Dan Fox of the Naval Research Laboratory at Stennis Space Center for most kindly providing MODAS $T, S$ fields. This work was funded by the Office of Naval Research, the Naval Oceanographic Office, and the Naval Postgraduate School.

\section{REFERENCES}

[1] SCSMEX Science Working Group (1995): The South China Sea Monsoon Experiment (SCSMEX) Science Plan. NASA/Goddard Space Flight Center, Greenbelt, Maryland, 65pp.

[2] P.C. Chu, M. D. Perry, E.L. Gottshall, and D.S. Cwalina, 2004: Satellite data assimilation for improvement of Naval undersea capability. Marine Technology Society Journal, 38(1), 11-23.

[3] D.N. Fox, W.J. Teague, C.N. Barron, M.R. Carnes and C.M. Lee (2002): The modular ocean data assimilation system (MODAS). J. Atmos. and Oceanic Technol., 19, 240-252.

[4] P.C. Chu, S.H. Lu, and Y.C. Chen (2001): Evaluation of the Princeton Ocean Model using the South China Sea Monsoon Experiment (SCSMEX) data. J. Atmos. Oceanic Technol., 18, 1521-1539.

[5] P.C. Chu, G.H. Wang, and C.W. Fan, 2004: Evaluation of the U.S. Navy's Modular Ocean Data Assimilation System (MODAS) using the South China Sea Monsoon Experiment (SCSMEX) data. Journal of Oceanography, 60, 1007-1021. 